\title{
Epigenetic silencing of $M A L$, a putative tumor suppressor gene, can contribute to human epithelium cell carcinoma
}

\author{
Wei Cao ${ }^{1,2}$, Zhi-yuan Zhang ${ }^{1,2^{*}}$, Qin $X^{1,2}$, Qiang Sun ${ }^{1,2}$, Ming Yan ${ }^{1,2}$, Jun Zhang ${ }^{1,2}$, Ping Zhang ${ }^{1,2}$, \\ Ze-guang $\operatorname{Han}^{2,3}$, Wan-tao Chen ${ }^{1,2^{*}}$
}

\begin{abstract}
Background: To identify new and useful candidate biomarkers in head and neck squamous cell carcinoma (HNSCC), we performed a genome-wide survey and found that Myelin and lymphocyte-associated protein (MAL) was a gene that was markedly down-regulated in HNSCC. Hence, we investigated the mechanism of MAL silencing and the effects of MAL on the proliferation, invasion, and apoptotic potential in HNSCC.

Results: MAL was significantly down-regulated in $91.7 \%$ of HNSCC specimens at the mRNA level as compared with adjacent normal tissues $(P=0.0004)$. Moreover, the relative transcript levels of the MAL gene were remarkably decreased by five-fold in nine HNSCC cell lines as compared with normal head and neck epithelium cells. MAL gene expression was restored in 44\%,67\%, and 89\% in HNSCC cell lines treated with TSA, 5-Aza-dC, and TSA plus 5-Aza-dC, respectively. Furthermore, bisulfate-treated DNA sequencing demonstrated that the two CpG islands (that is, $M_{1}$ and $M_{2}$ ) located in MAL promoter region were completely methylated in the HNSCC cell lines (CpG methylated ratio was more than 90\%), and only one CpG island (that is, $\mathrm{M}_{1}$ ) was partially methylated in HNSCC tissues (CpG methylated ratio between 20\% and 90\%). A significant reduction in cell proliferation and a change in the cell cycle profile were also observed in MAL transfectants. Matrigel assay demonstrated that the invasiveness of HNSCC cells significantly decreased. A significant increase in the population of apoptotic cells was observed in MAL transfected cells. The exogenous expression of the MAL gene suppressed malignant phenotypes, while the cell death induced by MAL gene transfer was a result of apoptosis as demonstrated by the induction of cleavage of the poly (that is, ADP-ribose) polymerase. Additionally, tumor growth was suppressed in cells expressing MAL as compared with cells not expressing MAL.
\end{abstract}

Conclusion: Our data suggest that the epigenetic inactivation of MAL, as a candidate tumor suppressor gene, can contribute to human epithelial cell carcinoma and may be served as a biomarker in HNSCC.

\section{Background}

Head and neck squamous cell carcinoma (HNSCC), which is a type of epithelial carcinoma, is the sixth most common cancer in the world [1]. However, surgery, radiotherapy, and chemotherapy have not sufficiently improved the five-year survival rate of patients with these devastating diseases in more than three decades. Despite ongoing efforts, no biomarkers have been identified yet. To search for useful biomarkers for the

\footnotetext{
*Correspondence: zhzhy@omschina.org.cn; chenwantao2002@hotmail.com 'Department of Oral and Maxillofacial Surgery, Ninth People's Hospital, Shanghai Jiao Tong University School of Medicine, Shanghai 200011, China Full list of author information is available at the end of the article
}

diagnosis, therapy, and prognosis of HNSCCs, highthroughput microarray analysis was used to identify genes that are differentially expressed in tumors [2-6]. In a previous study [7], we used an oligonucleotide microarray (Affymetrix HG-U95Av2) to select differentially expressed genes in 22 pairs of HNSCC and normal epithelial tissue from the same donors. Remarkably, the Myelin and lymphocyte-associated protein gene $(M A L)$, which is located on chromosome $2 \mathrm{q}$, was downregulated in HNSCC. The previous reports also described the similar down-modulation of $M A L$ gene expression in certain cancer types [8-13], indicating $M A L$ gene downregulation might be as a common

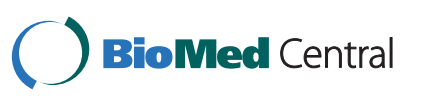

C 2010 Cao et al; licensee BioMed Central Ltd. This is an Open Access article distributed under the terms of the Creative Commons Attribution License (<url>http://creativecommons.org/licenses/by/2.0</url>), which permits unrestricted use, distribution, and reproduction in any medium, provided the original work is properly cited. 
molecular event contributing to initiation and/or progression of cancers. Based on this hypothesis, $M A L$ was chosen for further investigation.

The $M A L$ gene was originally identified by Alonso and Weissman during a search for differentially expressed genes in T-cell development [14]. The MAL protein, which is encoded by $M A L$, is also to be a vesicle integral protein. It has a molecular weight of approximately $17 \mathrm{kDa}$ (VIP17) and is present in Schwann cells, in oligodendrocytes, and in the epithelial cells of the kidney, stomach, and large intestine [15]. It spans the membrane four times and is structurally similar to members of the tetraspan family. In every cell in which it is expressed, MAL is associated with glycosphingolipids; it is also thought to be involved in the organization, transport, and maintenance of glycosphingolipid-enriched membranes, which are resistant to detergent extraction. Because these glycosphingolipid-enriched membranes are thought to be part of apical transport machinery [16], MAL as a proteolipid protein is involved in normal apical transport and accurate sorting in Madin-Darby canine kidney cells $[17,18]$. The recent data on $M A L$ gene down-regulation in primary human epithelial malignancies suggest that the loss of the $M A L$ gene may be closely linked with a variety of human epithelial malignancies $[8,19,20]$. Moreover, Beder et al reported that $M A L$ gene mRNA is downregulated in metastatic HNSCC tumors as compared to that in primary HNSCC tumors, implying that the decreasing $M A L$ expression could contribute to metastatic potential of HNSCC [21]. The use of the MAL protein as a predictive biomarker to benefit for patients undergoing chemotherapy was also statistically analyzed in breast and ovarian cancers $[11,22]$. However, the molecular mechanism by which of $M A L$ gene downregulation and contribution in HNSCC initiation or progression remain unclear. Moreover, whether $M A L$ gene might be a valuable diagnostic or therapeutic biomarker for HNSCC need to be further investigated.

In this study, we examined the expression of MAL transcripts in HNSCC samples, adjacent normal epithelial tissues and HNSCC cell lines using real-time RT-PCR and semi-quantitative RT-PCR. We found that full-length isoform a is the only transcript variant in head and neck epithelium; $M A L$ transcript levels are down-regulated in HNSCC tissues and HNSCC cell lines as compared with adjacent normal tissues. Next, we investigated the mechanism of $M A L$ gene down-regulation. The aberrant epigenetic alteration contributes to the silencing of the $M A L$ gene in HNSCC. Furthermore, to assess the functional role of $M A L$ in HNSCC, we evaluated the effect of ectopic $M A L$ expression on Tca cells, Tca-M and $\mathrm{Tb}$ cells, which are HNSCC-derived cell lines. Our results show that exogenous expression of MAL in HNSCC cell lines inhibited the proliferation, invasion, and induced apoptosis of cancer cells in vitro and tumorigenicity in vivo.

\section{Results \\ Identification and expression of MAL transcript shows variations in head and neck squamous epithelium}

Alonso et al [23] previously reported that sequence analysis of the human T-cell-specific MAL gene revealed four exons, each encoding a hydrophobic, presumably membrane-associated, segment and its adjacent hydrophilic sequence. Alternative splicing produces four transcript variants, which vary by the presence or absence of alternatively spliced exons 2 and 3 . To determine whether alternatively spliced isoforms of $M A L$ were expressed in head and neck squamous epithelium, a pair of PCR-primers spanning exon 1 and exon 4 was designed to discriminate the transcript levels of the four variants using semi-quantitative RT-PCR analysis (Figure $1 \mathrm{~A}, 1 \mathrm{~B})$. Our results showed that the variant a, which is the longest of the isoforms is the only transcript variant in head and neck squamous epithelium.

\section{$M A L$ is frequently down-regulated in HNSCCs and cell lines}

As our microarray data indicated, $M A L$ expression was reduced remarkably in HNSCC as compared to adjacent normal tissues. To investigate whether $M A L$ contributes to HNSCC progression, real-time RT-PCR and semi-quantitative RT-PCR analyses were performed to investigate mRNA levels of $M A L$ in 48 HNSCC specimens. Out of the 48 cases examined, 44 (91.7\%) HNSCC specimens had at least a two-fold decrease in $M A L$ mRNA levels as compared to non-tumorous tissues $(P<0.01$, Figure $2 \mathrm{~A}, 2 \mathrm{~B})$. Meanwhile, the expression levels of $M A L$ mRNA in a panel of nine HNSCC cell lines and the immortalized oral keratinocyte line HIOEC were detected during semi-quantitative RT-PCR analysis. As shown in Figure 2C, $M A L$ transcript levels in the HNSCC cell lines and HIOEC cells were significantly lower than in the case of normal epithelial cells $(P<0.01)$.

\section{The transcription of MAL is associated with promoter methylation in HNSCCs}

Increasing evidence has shown that epigenetic silencing of tumor suppressor genes because of aberrant DNA hypermethylation and histone modification is essential to carcinogenesis and metastasis [20,24]. To verify whether $M A L$ gene promoter hypermethylation contributed to $M A L$ down-regulation, nine HNSCC cell lines were treated with 5 -Aza-dC in conjunction with the TSA. Our result showed that $M A L$ gene transcription was reactivated in $67 \%(6 / 9)$ of the HNSCC cell lines after treatment with 5 -Aza-dC, while $89 \%(8 / 9)$ of the 


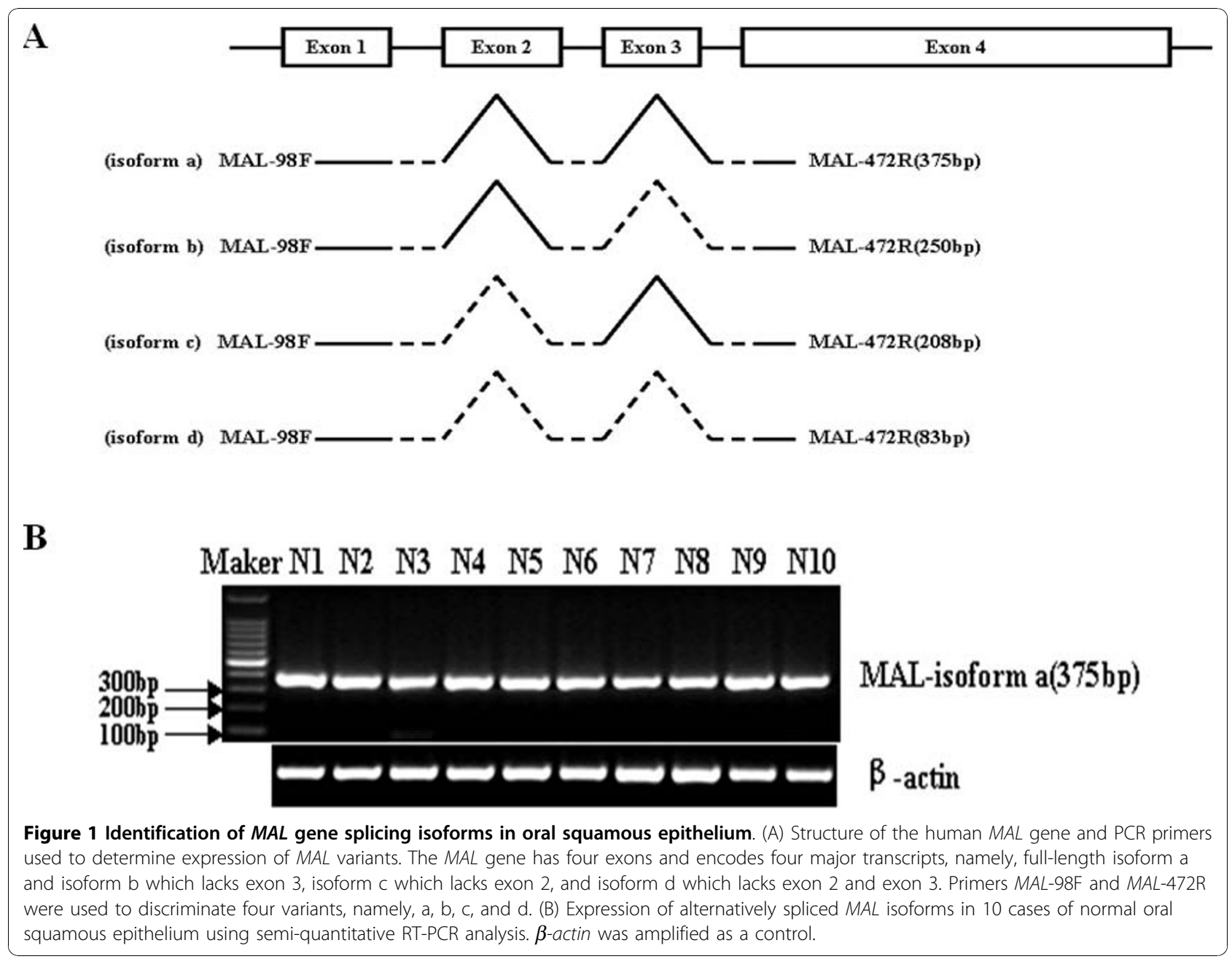

cell lines showed $M A L$ reactivation because of simultaneous treatment with 5-Aza-dC and TSA. In addition, the levels of $M A L$ mRNA increased in 44\% (4/9) of HNSCC cell lines treated with TSA alone as compared to the untreated control (Figure 3A). To further explore the epigenetic mechanism, the putative CpG islands around $M A L$ transcriptional start site (TSS) were screened by using bioinformatics tools. Two major CpG islands M1 (distance to TSS, -626 to $-385 \mathrm{bp}$ ) and M2 (distance to TSS, +390 to $+669 \mathrm{bp}$ ) were found. Next, to evaluate the methylation status of the two major CpG islands around the MAL TSS, bisulfate-treated DNA sequencing was performed in two randomly selected HNSCC cell lines and seven pairs of HNSCCs from 48 cases. The results demonstrated that both $\mathrm{CpG}$ islands (that is, M1 and M2) were completely methylated in the HNSCC cell lines (CpG methylated ratio more than $90 \%)$ relative to normal primary head and neck epithelial cells $(P<0.01)$. However, the methylation level of the CpG island (that is, M1) in the MAL putative promoter but not the $\mathrm{CpG}$ island in the intragenic regions (that is, M2) was significantly higher in all seven HNSCC cases than in the corresponding adjacent noncancerous tissues $(P<0.01$, Figure $3 \mathrm{~B}, 3 \mathrm{C})$

MAL inhibits cell proliferation and colony formation, thus inducing G1-phase arrest

To evaluate whether $M A L$ functions as a tumor suppressor in HNSCC cells, we assessed the effect of MAL expression on cell proliferation and colony formation. Based on the MAL expression pattern in HNSCC-derived cell lines (Figure 2C), we transiently transfected mammalian expression vectors containing $M A L$ into Tca, Tca-M and $\mathrm{Tb}$ cells, all of which lacked endogenous MAL expression. MAL over-expression suppressed the growth and colony formation ability of these cells relative to mock-transfected controls $(P<0.01$, Figure $4 \mathrm{~A}$ and $4 \mathrm{~B})$. To validate which cell population was altered most remarkably in cell cycle distribution, flow cytometry was performed in randomly selected cell line. Our results showed that the $M A L$-transfected cells had a marked increase in the number of cells in the G1-phase as 


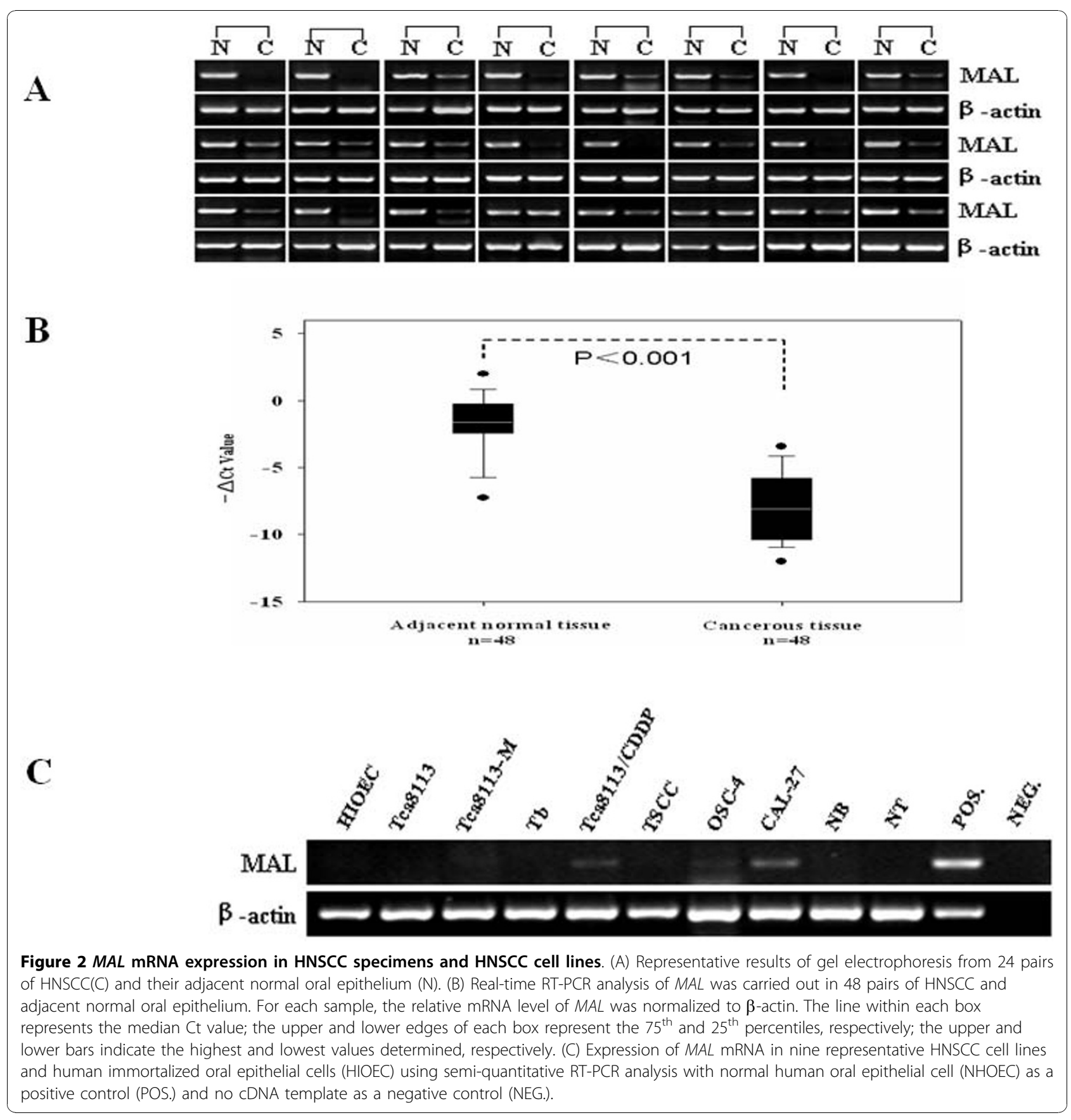

compared with the mock-transfected cells $(43.58 \% \pm 5 \%$ vs. $59.61 \% \pm 6 \%, P<0.05$, Figure 4 C.) This indicates that the cells expressing exogenous MAL become blocked at the $\mathrm{G} 1 / \mathrm{S}$ transition.

Induction of apoptosis in HNSCC cells by ectopic MAL expression

To determine whether the inhibitory effect of MAL expression on cells was caused by apoptosis, two independent assays were performed. As shown in Figure 5A, MAL expression induced an increase in the number of sub-G1 cells. After 24 hours, 48 hours and 72 hours of transient transfection, the apoptotic rates of the $M A L$-transfected Tca cells were $1.14 \%, 4.04 \%$, and $11.71 \%$, respectively, as compared with $1.07 \%, 2.20 \%$, and $4.01 \%$, respectively, for the control cells ( 48 hours and 72 hours, $P<0.01$ ). In addition, we assessed the fraction of cells with positive staining for 7-amino-actinomycin (7-AAD) and Annexin V-PE in $M A L$-transfected Tca cells (7.54\%) and the control cells (2.60\%) (Figure 5B). Furthermore, we also examined the 


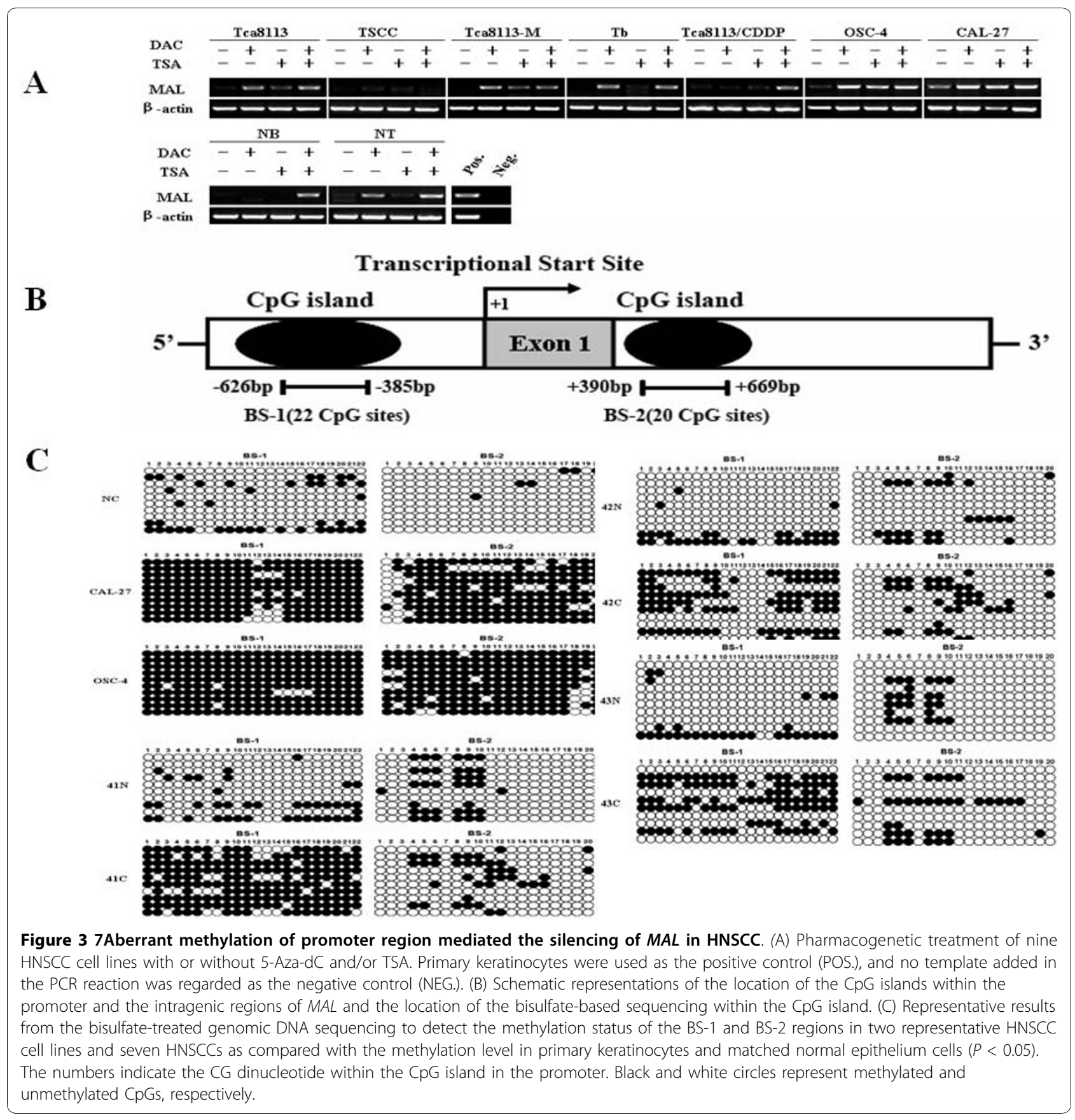

expression level of poly (ADP-ribose) polymerase (PARP) cleavage, which is a hallmark of apoptosis [25], using Western blot analysis after transient transfection with an empty vector or $M A L$ at 48 hours, 72 hours (Figure $5 C$ ).

Effect of exogenous MAL expression suppresses invasion of HNSCC cell line

In vitro invasion assays were performed to determine the effect of $M A L$ on cell invasion using BD BioCoat ${ }^{\mathrm{TM}}$ Matrige$\mathrm{I}^{\mathrm{TM}}$ Invasion Chambers. The Matrigel ${ }^{\mathrm{TM}}$ matrix served as a reconstituted basement membrane in vitro. As shown in Figure $6 \mathrm{~A}$ and $6 \mathrm{~B}$, the number of cells that invaded through the transwell membrane in clone \#12, which expresses $M A L(65 \pm 32)$, was significantly lower than those in clone \#6, which does not express $M A L(178 \pm 44, P<0.01)$.

Ectopic expression of MAL reduces tumor growth in nude mice

Since $M A L$ expression represses the malignant properties of HNSCC cells in vitro, we also evaluated the effect of 


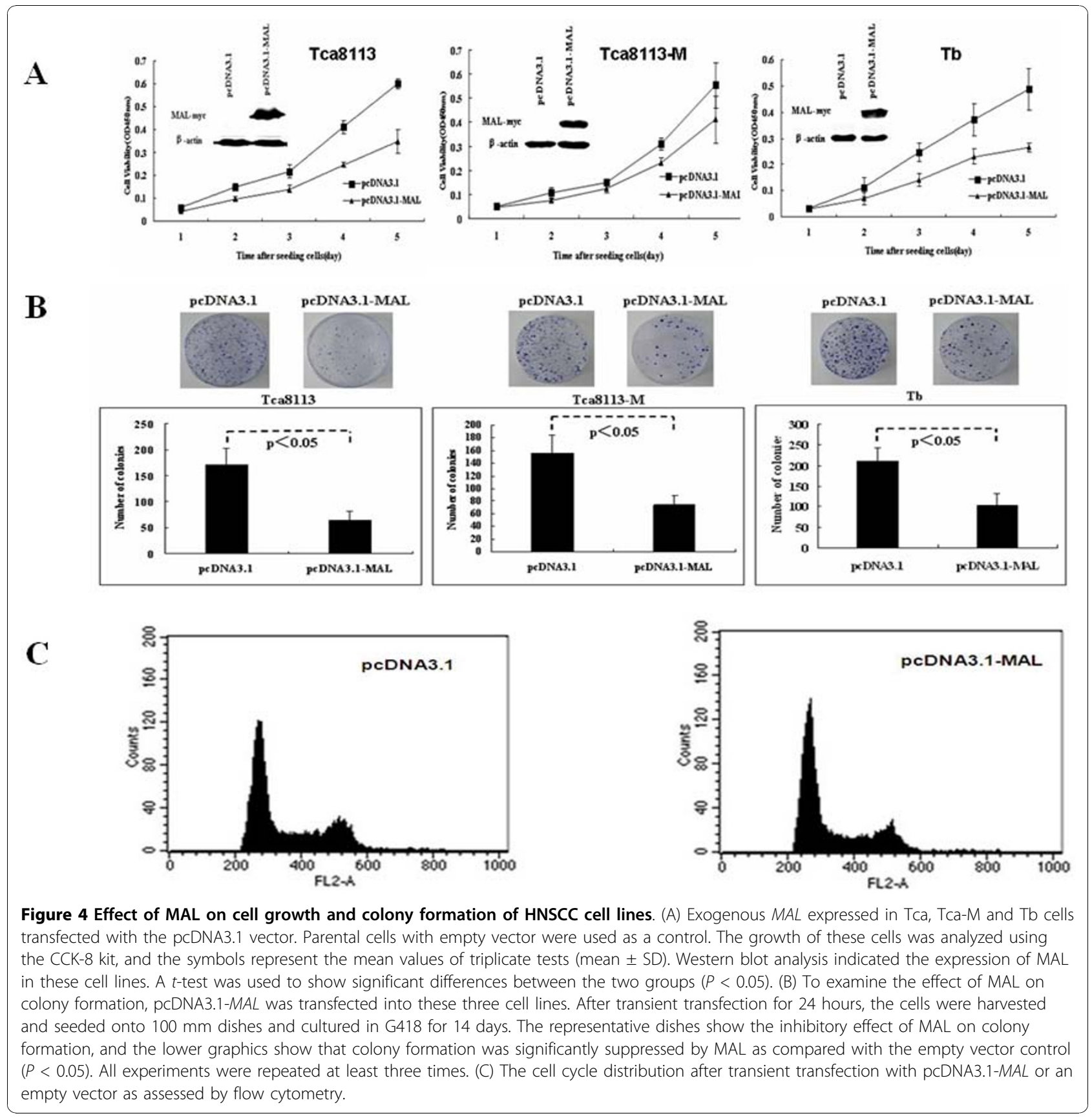

$M A L$ on the tumorigenicity in a xenograft model. For this purpose, Tca cells expressing $M A L$ (clone \#12) and cells not expressing $M A L$ (clone \#6) were injected subcutaneously into the left and right posterior limb of nude mice, respectively. After four weeks, the animals were executed, and the tumor weights were measured. The results showed that tumor growth was significantly reduced in $M A L$-expressing (clone \#12) cells as compared to $M A L$ non-expressing (clone \#6) cells $(P<0.05$, Figure $6 \mathrm{C})$.

\section{Discussion}

Several research groups have recently extensively investigated the transcriptome and proteome of HNSCCs using high-throughput microarray technology [26-29]. The aims were to identify genes that were potentially involved in HNSCC progression and to find diagnostic and prognostic gene expression signatures. These molecular signatures could provide key clues to early diagnosis; they could also guide prognosis and the design and 


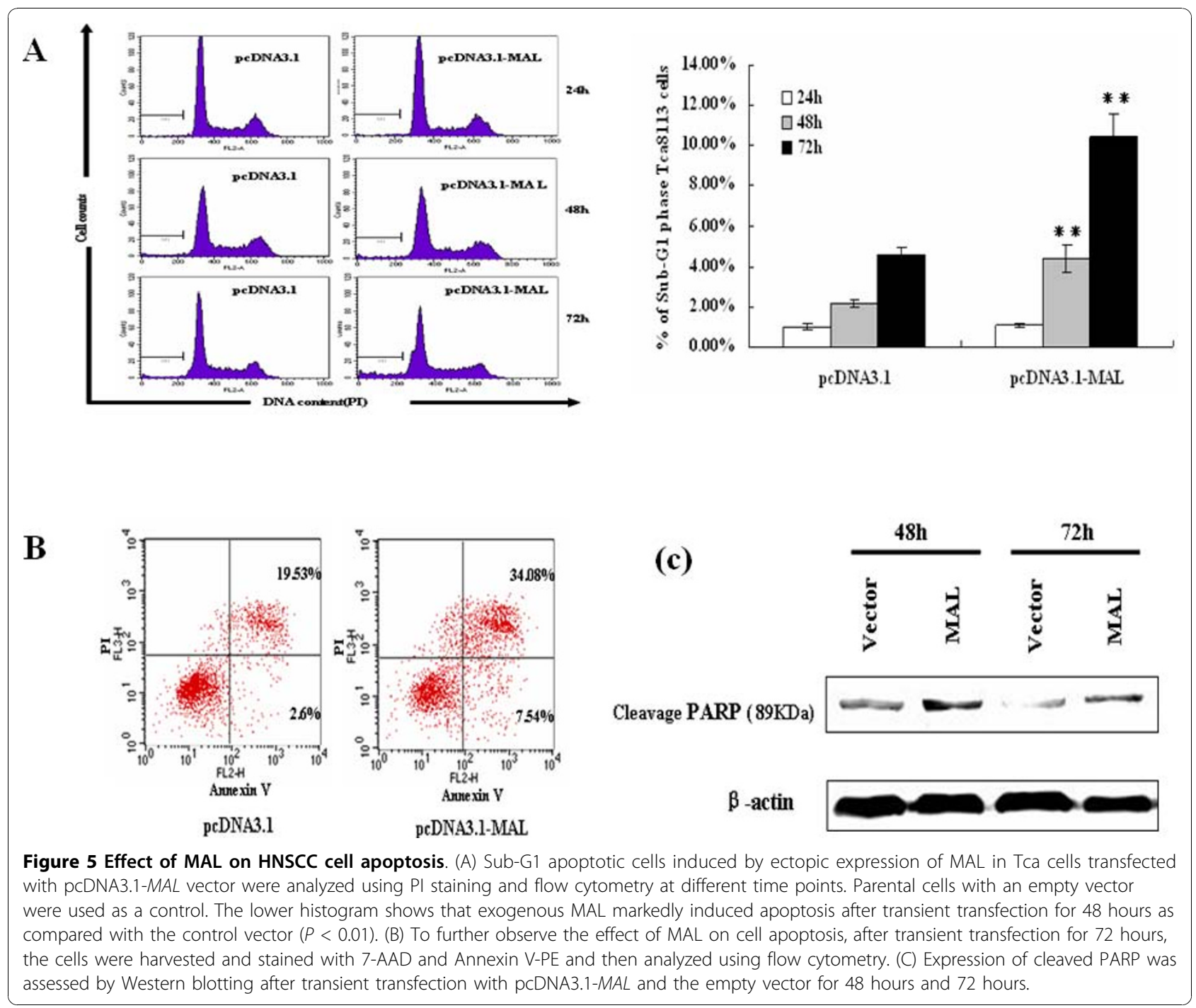

monitoring of new therapeutic approaches [30]. In our previous study using cDNA microarray analysis, we identified $M A L$ as a remarkably down-regulated gene in HNSCCs as compared with adjacent normal tissues. Furthermore, Lallemant et al [31] reviewed 23 papers published between March 2000 and November 2007 to find that the $M A L$ gene was down-regulated in HNSCCs, which is consistent with our microarray data. Thus, we hypothesized that the $M A L$ gene could be a candidate HNSCC-specific molecular marker. However, although $M A L$ has been implicated in the overall apical delivery of secretory proteins and transmembrane proteins [32,33], the role of $M A L$ in HNSCC progression has not been addressed yet. In this study, our data demonstrated a close correlation of MAL expression with carcinogenesis and/or progression of human HNSCC (Figure 2).
The genetic and epigenetic silencing of tumor suppressor genes is considered a vital molecular event in the development and progression of HNSCC [34]. Although $M A L$ is located at chromosome $2 \mathrm{q} 13$, a region that is involved in large homozygous deletions in juvenile nephronophthisis [35], no deletions or mutations have been reported yet with respect to human cancer. However, the previous studies indicated that DNA methylation level of $M A L$ promoter was increased in various types of carcinoma [9,36-38]. Moreover, the induction of $M A L$ gene expression by DAC or TSA was described by some studies $[8,9,11]$. Furthermore, in addition to hypermethylation of $M A L$ gene promoter in $9(45 \%)$ out of 20 HNSCC cell lines, Beder et al showed that loss of heterozygosity (LOH) still occur in $9(30 \%)$ of 29 primary HNSCCs [21]. Considering these findings, here we hypothesized that $M A L$ was inactivated in 


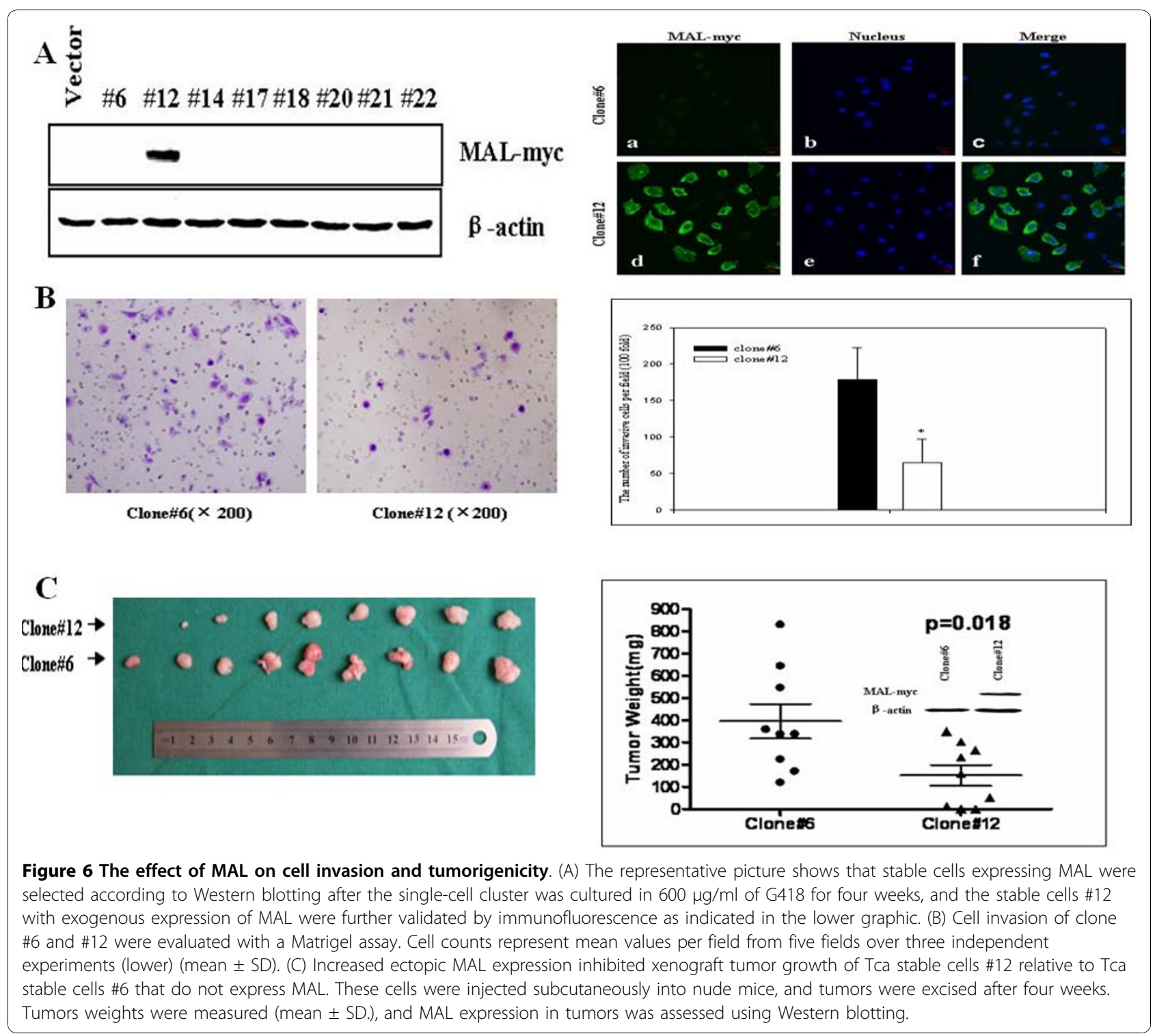

HNSCC due mainly to the desregulated epigenetic modifications, although not exclude the possibility that the gene dosage of $M A L$ such as LOH affects its expression.

To evaluate effect of the DNA methylation and histone acetylation status on $M A L$ expression in HNSCC cell lines, in this study, we used pharmacological treatment on these cells with the demethylation agent DAC in conjunction with (and without) the histone deacetylase inhibitor TSA. Consistent with above findings, our results showed that the $M A L$ gene was reactivated in most HNSCC cell lines (Figure 3A), suggesting that DNA promoter methylation and histone deacetylation as major factors were involved in silencing the $M A L$ gene. Although $M A L$ gene hypermethylation in HNSCC cell lines was found by Beder et al [21], more detailed DNA hypermethylation status within $M A L$ gene promoter in
HNSCC cells, especially in paired HNSCCs and corresponding normal tissues should be further evaluated. Moreover, the correlation between $M A L$ transcriptional level and DNA methylation status in these HNSCC specimens needs to be elucidated. To address these issues, we first used bioinformatics tools to determine whether there were $\mathrm{CpG}$ islands in the regulatory elements of the $M A L$ gene from 2,000 bp upstream to $200 \mathrm{bp}$ downstream of the transcription start site. In addition, we also examined the sequences of the intragenic regions. Interestingly, two major CpG islands were identified. They were located at upstream region, $-626 \mathrm{bp}$ to -385 bp (M1, including $22 \mathrm{CpG}$ sites) and downstream region, +390 bp to +669 bp (M2, including $20 \mathrm{CpG}$ sites) of $M A L$ TSS (Figure $3 \mathrm{~B}$ ), respectively. It should be pointed out that these $\mathrm{CpG}$ islands have never been 
included in other studies in various cancers [9-11,36,37]. In this study, we employed bisulfate-treated DNA sequencing to measure promoter hypermethylation, which allows for an objective, robust, and global assessment of promoter methylation status as compared with methylation-specific PCR. Our data indicated that both CpG islands (M1 and M2) around the MAL TSS were completely methylated in HNSCC cell lines relative to normal primary head and neck epithelium cells $(P<$ 0.01 ). Only the methylation level of the first CpG island (that is, M1) in the $M A L$ promoter was significantly higher in all seven HNSCC cases as compared to the corresponding adjacent noncancerous tissues $(P<0.01)$, suggesting $\mathrm{M} 1$ is a major hypermethylated region around TSS of MAL gene in HNSCC. Accordingly, $M A L$ transcript levels were decreased in all seven HNSCC cases as compared to the corresponding adjacent noncancerous tissues. Based these data and findings in other cancers, we proposed that DNA hypermethylation of the $M A L$ regulatory elements could be a major contributor to the downregulation of $M A L$ in HNSCC. However, it should be emphasized that, in addition to DNA hypermethylation, histone modification such as deacetylation status also affected $M A L$ expression in HNSCC. Further study on this issue would provide the novel insight to elucidate the mechanism by which both DNA methylation and histone deacetylation play a synergic role in silencing of $M A L$ gene.

MAL was first postulated as tumor suppressor protein by Mimori et al [8]. The reactivated expression of $M A L$ gene exerts an inhibitory effect on motility and tumorigenicity of esophageal cancer. Moreover, MAL can induce apoptosis of cancer cells. However, the effect of MAL on HNSCC cells was unclear, due to the lack of in vitro and in vivo functional experiments for $M A L$ gene in HNSCC. Considering the particularity of HNSCC in epidemiology which is remarkably different from other cancer types, as well as the distinct molecule signatures in initiation and progression, in the present work, we evaluated the functional role of $M A L$ gene in three HNSCC cell lines in order to determinate whether MAL might be as a therapeutic target for HNSCC. Our experimental results showed that $M A L$ gene overexpression could exert strong antiproliferative effects on HNSCC cells by blocking cells at the G1/S transition. Furthermore, the Annexin V-PE and 7-AAD staining, along with the increasing cell population in sub-G1 phase and elevating cleaved PARP level revealed that the inhibitory effect of MAL on cell proliferation was through intensively inducing early apoptosis of cancer cells. Accordingly, our results also demonstrated that exogenous expression of $M A L$ could suppress the invasive ability and tumorigenicity of HNSCC cells, which was consistent with the findings described in esophageal cancer.

\section{Conclusion}

Our study shows that $M A L$ inactivation is functionally involved in HNSCC progression and that the $M A L$ gene promoter is hypermethylated, which is a predictor of the reduced MAL mRNA expression levels in both HNSCC tissues and cell lines. As such, our study strongly suggests that the $M A L$ gene may be a candidate tumor suppressor in HNSCC and a potential and novel therapeutic target for HNSCC.

\section{Methods}

\section{Carcinomas and control specimens}

The samples were collected at the Department of Oral and Maxillofacial Surgery at the Affiliated Ninth People's Hospital of Shanghai Jiao Tong University School of Medicine from 2000 to 2009 . All samples were obtained by surgery and then quickly frozen in liquid nitrogen until DNA and total RNA were extracted. Normal tissues adjacent to the tumors were also obtained with the patient's consent. Tumors were classified histologically and staged according to the tumor-node-metastasis (TNM) classification of malignant tumors [39]. Tumor pathological grade was assessed according to standard criteria [40].

\section{Cell lines}

The human cell lines Tca8113 (Tca), Tca8113-M (Tca-M), Tb, Tca/CDDP (established in the Ninth People's Hospital, Shanghai Jiao Tong University School of Medicine), TSCC (kindly provided by Wuhan University, School of Dentistry, China), OSC-4 (kindly provided by Kochi University, School of Medicine, Japan), NB and NT (kindly provided by Nagasaki University School of Dentistry, Japan) were cultured in RPMI-1640 medium (GIBCO BRL, USA) supplemented with $10 \%$ heatinactivated fetal bovine serum (FBS; GIBCO BRL, NY, USA), penicillin (100 units/ml) and streptomycin (100 $\mu \mathrm{g} / \mathrm{ml}$ ) at $37^{\circ} \mathrm{C}$ in a humidified $5 \% \mathrm{CO} 2$ atmosphere. CAL-27 (American Type Culture Collection, Manassas, VA, USA) was cultured in Dulbecco's modified Eagle medium (DMEM; GIBCO BRL, USA) supplemented with $10 \%$ heat-inactivated FBS), penicillin (100 units $/ \mathrm{ml})$ and streptomycin $(100 \mu \mathrm{g} / \mathrm{ml})$ at $37^{\circ} \mathrm{C}$ in a humidified $5 \%$ $\mathrm{CO} 2$ atmosphere. The immortalized oral keratinocyte line HIOEC from primary normal human oral epithelial cells infected with HPV16E6E7 (established in the Ninth People's Hospital, Shanghai Jiao Tong University School of Medicine) was cultured in a defined keratinocyte serum-free medium (KSFM; GIBCO BRL, USA).

\section{RNA preparation in semi-quantitive reverse transcription- polymerase chain reaction (RT-PCR) analysis}

Total RNA was extracted from each tissue sample and cell line using the TRIZOL reagent (Invitrogen, San Diego, USA). The quality of the total RNA samples was 
determined by electrophoresis using formaldehyde agarose gels, and the $18 \mathrm{~S}$ and $28 \mathrm{~S}$ RNA bands were visualized under ultraviolet light. Then $2 \mu \mathrm{g}$ of total RNA was reverse-transcribed directly to cDNA using a reverse transcription kit (Promega, Madison, USA) following the manufacturer's instructions in a total volume of $25 \mu \mathrm{l}$. The primer sequences used were as follows: $M A L$ forward, 5'-CAGTGGCTTCTCGGTCTT-3'; MAL reverse, 5'-AGCAGAGTGGCTATGTAGGA-3'; $\beta$-actin forward, 5'-TCACCCACACTGTGCCCATCTACGA-3'; and $\beta$ actin reverse, 5'-CAGCGGAACCGCTCATTGCCAATGG-3'; Each primer was added at a final concentration of $0.5 \mu \mathrm{M}$ to a $15 \mu \mathrm{l}$ reaction mixture in PCR buffer containing $1 \mu \mathrm{l}$ of cDNA, $0.25 \mathrm{mM}$ of each dNTP, $1.5 \mathrm{mM}$ of $\mathrm{MgCl}_{2}$, and 2.5 units of Taq DNA polymerase. An initial denaturation was carried out for 5 minutes at $94^{\circ} \mathrm{C}$, and 35 cycles were performed with the following PCR program: denaturing at $94^{\circ} \mathrm{C}$ for 30 seconds, annealing at $45-60^{\circ} \mathrm{C}$ for 30 seconds for $M A L$ and $55^{\circ} \mathrm{C}$ for 30 seconds for $\beta$-actin, and elongation at $72^{\circ} \mathrm{C}$ for $30 \mathrm{sec}-$ onds. This program was completed with a final extension at $72^{\circ} \mathrm{C}$ for 5 minutes. Ethidium bromide-stained bands were visualized using UV transillumination, and fluorescence intensity was quantified using the FR-200 system (FuRi, Shanghai, China). The data from semi-quantitive PCR reactions were normalized against the expression of $\beta$-actin from three independent experiments \pm the standard deviation (SD). All RT-PCR data were from at least three independent experiments.

\section{Real-time PCR}

All real-time PCR reactions were performed using a Thermal Cycler Dice ${ }^{\text {ru }}$ Real Time System (Takara) and the SYBR Premix Ex Taq ${ }^{\text {in }}$ reagents kit (Takara, Japan). The real-time PCR was performed in a final volume of $15 \mu \mathrm{l}$ with $1.5 \mu \mathrm{l}$ of template cDNA at a concentration of $20 \mathrm{ng} / \mu \mathrm{l}$ with $7.5 \mu \mathrm{l} \mathrm{SYBR}$ green I fluorescent dye and $20 \mathrm{pM}$ of each primer for the target gene and the house keeping gene ( $\beta$-actin). The primer sequences included sense 5'-GGGCTGGGTGATGTTCGT-3' and anti-sense 5'-TAGGCTGCGTCCAAGGTG-3' for MAL (117 bp) and sense 5'-CCTGGCACCCAGCACAAT-3' and antisense 5'-GGGCCGGACTCGTCATACT-3' for $\beta$-actin. Results of real-time PCR were represented as $\mathrm{Ct}$ values, where $\mathrm{Ct}$ was a fraction defined as the cycle number at which the sample fluorescent signal passes a given threshold above the baseline. $\Delta \mathrm{Ct}$ was the difference in the $\mathrm{Ct}$ values derived from the specific genes after being assayed and $\beta$-actin. The $\mathrm{N}$-fold differential expression in a specific gene of a tumor sample, matched normal tissue and cell lines were expressed as $2^{\Delta \mathrm{Ct}}[17]$. The significance level was defined as a $P$-value of less than 0.01 .

\section{Induction of gene expression by 5-Aza-dC, TSA and 5-Aza-dC in combination with TSA}

To induce demethylation of promoter prior to evaluation for induction of $M A L$ expression, all of the abovementioned HNSCC cell lines were treated with $2 \mu \mathrm{M}$ 5-Aza-dC, which is the DNA demethylation reagent, for 72 hours, $0.5 \mu \mathrm{M}$ TSA, which is a specific inhibitor of histone deacetylase, for 24 hours, or $2 \mu \mathrm{M} 5$-Aza-dC for 72 hours plus $0.5 \mu \mathrm{M}$ TSA for 24 hours.

\section{Direct bisulfate sequencing}

Genomic DNA was treated with bisulfate as previously described [18]. Briefly, $1 \mu \mathrm{g}$ genomic DNA was denatured by incubation with $0.2 \mathrm{M} \mathrm{NaOH}$. Aliquots of $10 \mathrm{mM}$ hydroquinone and $3 \mathrm{M}$ sodium bisulfate $(\mathrm{pH}=5.0)$ were added, and the solution was incubated at $50^{\circ} \mathrm{C}$ for 16 hours. To analyze the DNA methylation status of the CpG islands of $M A L$ promoter in HNSCCs and cell lines, regions enriched in $\mathrm{CpG}$ islands were amplified in bisulfate-treated genomic DNA using the primers CpG island I, forward, 5'-GGAGTAATTTTTTATTTTTAGGTAGA3'; reverse, 5'-AAАТTTAAАТCTCСТTCATTTTTCC-3'; CpG island II, forward, 5'-TTTAATTGGGGTTAGATGTAGGTAG-3'; and reverse, 5'-AAAAACTTTAAAAAACCAAAAAAAA-3'. The PCR products were then subcloned into a pMD18-T vector (TaKaRa Inc. Japan) for DNA sequencing on an ABI 3730 sequencer.

\section{Western blotting}

The cells were washed with PBS twice and lysed for 30 minutes in $25 \mathrm{mM}$ Tris- $\mathrm{HCl}$ with a $\mathrm{pH}$ of 7.5 and containing $150 \mathrm{mM} \mathrm{NaCl}, 5 \mathrm{mM}$ EDTA, and 1\% Triton $\mathrm{X}-100$ at $4{ }^{\circ} \mathrm{C}$. The lysate was homogenized by passing the sample through a 22-gauge needle. The glycolipidenriched membrane (GEM) was isolated from the lysate by equilibrium centrifugation for Western blot analysis with an anti-c-myc monoclonal antibody (mAb). In brief, for immunoblot analysis, the GEM samples were run on SDS-PAGE in 12\% acrylamide gels and transferred onto nitrocellulose membranes (Amersham, NA, England). After blocking with 5\% nonfat dry milk and 0.05\% Tween-20 in PBS, blots were incubated with antic-myc mAb (Santa Cruz Biotechnology, CA, USA), anticleavage PARP polyclonal antibody (Cell signaling, MA, USA) and anti- $\beta$-actin mAb (Sigma, St Louis, MO, USA) at the optimized dilutions. Bands were detected using an IRDye ${ }^{\mathrm{Tm}} 800$ Conjugated Affinity Purified AntiMouse IgM antibody (Rockland, Gilbertsville, PA, USA). The membrane was then washed several times and scanned using the Odyssey infrared imaging system (LICOR, Lincoln, NE, USA) at an 800 channel wavelength and analyzed with Odyssey software. 


\section{Plasmid construction and the transient and stable transfection of constructs}

To generate the $M A L$ expression vector, the open reading frame of human $M A L$ cDNA was cloned into the eukaryotic expression vector pcDNA3.1 (Invitrogen, San Diego, CA, USA) and fused to a COOH-terminal Myc tag. The primers used for the amplification of the openreading frame of the $M A L \mathrm{cDNA}$ were GCGAATTCACCATGGCCCCCGCAGCGGCGACG (forward primer), with an EcoRI site, and GCAAGCTTGCTGAAGACTTCCATCTGATTAAAG (reverse primer), with a HindIII site without the stop codon. The amplified $M A L$ gene product was purified using a Qiaquick PCR Purification Kit (Qiagen, Chatsworth, CA, USA), cut with EcoRI and HindIII and ligated with the Ligation Mix (TakaRa, Dalian, China) into the respective EcoRI and HindIII sites on the eukaryotic expression vector pcDNA3.1. For transient transfection, the cells were transfected with various plasmids at about $80 \%$ confluence using the Lipofectamine ${ }^{\mathrm{rm}} 2000$ (Invitrogen, San Diego, CA, USA) reagent according to the manufacturer's instructions. To generate stable MAL-expressing cell lines, cells were selected with G418 $(600 \mu \mathrm{g} / \mathrm{ml})$ for two weeks, and drug-resistant cells were screened using Western blot analysis with the anti-human c-myc mAb to detect MAL-myc. The clones that exhibited positive immunoreactivity were maintained in G418 $(300 \mu \mathrm{g} / \mathrm{ml})$ medium. Mock-transfected, $M A L$-transfected (but not MAL-expressing) and MAL-expressing stable cells were denoted as 3.1-vector, clone \#6, and clone \#12, respectively.

\section{Cell-proliferation assay}

Cell-proliferation assay was performed to analyze the proliferation potential of transiently transfected empty vector and $M A L$-transfected cells. To this end, we used the Cell-Counting Kit (CCK)-8 (Dojindo, Kumamoto, Japan). Briefly, the cells were harvested and plated in 96-well plates at $1 \times 10^{3}$ cells per well and maintained at $37^{\circ} \mathrm{C}$ in a humidified incubator. At the indicated time points, $10 \mu \mathrm{l}$ of the CCK- 8 solution was added into the triplicate wells and incubated for 1 hour, and the absorbance at $450 \mathrm{~nm}$ was measured to calculate the number of vital cells in each well. Measurements were performed in triplicate, and the Mean $( \pm S D)$ optical density (OD) was reported.

\section{Colony Formation assay}

Twenty-four hours after transfection, the cells $\left(1 \times 10^{5}\right.$ cells per plate) were plated in 100-mm culture dishes and incubated with $600 \mu \mathrm{g} / \mathrm{ml}$ of G418 for 14 days to allow for colony formation. The colonies were then washed twice with PBS, fixed with $70 \%$ ethanol and stained with 0.1\% Coomassie Brilliant Blue R-250.
Colonies of more than 50 cells were counted under a dissecting microscope. The data from colony formation were shown as means $( \pm \mathrm{SD})$ from at least three independent experiments, each performed in triplicate.

\section{Cell cycle distribution assay}

Empty vector and $M A L$-transfected cells at the logarithmic growth phase were harvested, and single-cell suspensions containing $1 \times 10^{6}$ cells were permeabilized with $70 \%$ ethanol. The cells were then labeled with $50 \mu \mathrm{g} / \mathrm{ml}$ of propidium iodide (PI) and treated with $250 \mu \mathrm{g} / \mathrm{ml}$ of RNase at $4^{\circ} \mathrm{C}$ for 30 minutes. Analysis was performed using FACS Calibur (BD Biosciences, San Jose, CA, USA) and analyzed using Cell Quest Software (BD Biosciences, San Jose, CA, USA). The data represent the Means $( \pm \mathrm{SD})$ from at least three independent experiments.

\section{Apoptosis assay}

The cells were harvested 24 hours, 48 hours, and 72 hours after transient transfection. Then they were washed once in PBS, permeabilized with $70 \%$ ethanol for 20 minutes and stored at $-20^{\circ} \mathrm{C}$ overnight. The cells were then subsequently washed with $\mathrm{PBS}$ and stained with $50 \mu \mathrm{g} / \mathrm{ml}$ of propidium iodide at $4^{\circ} \mathrm{C}$ for $30 \mathrm{~min}$ utes. Apoptotic cells were assessed by flow cytometry for sub-G1 DNA content. Meanwhile, apoptosis was assessed using Annexin V-PE staining 72 hours after transfection. Then, these cells were quantified by flow cytometry using the Annexin V-PE Apoptosis Detection Kit (BD Biosciences, San Jose, CA, USA) according to the manufacture's protocols. Briefly, floating cells and trypsinized adherent cells were pooled and resuspended in $100 \mu \mathrm{l}$ of Annexin V-PE Binding Buffer. Then $5 \mu \mathrm{l}$ of Annexin V-PE and $5 \mu$ of 7 -AAD were added, and the cells were incubated for 15 minutes at $25^{\circ} \mathrm{C}$. The cells were then resuspended in $400 \mu \mathrm{l}$ of the Annexin V-PE binding buffer and analyzed immediately by flow cytometry. Then 10,000 events were scored by the FACSCalibur and analyzed using the Cell Quest software.

\section{Confocal microscope}

Stable cells, that is, clone \#6 and clone \#12, were grown on coverslips and washed once with ice-cold PBS and fixed for 30 minutes in $4 \%$ paraformaldehyde at $4^{\circ} \mathrm{C}$. For immunostaining, the fixed cells were permeabilized with $0.1 \%$ Triton X-100 in PBS for 5 minutes, washed and blocked with PBS containing 0.05\% Tween-20 and 5\% horse serum (HS) for 30 minutes at room temperature, and incubated with a 1:500 dilution of anti-c-myc mAb in PBS supplemented with $0.05 \%$ Tween-20 and 5\% HS in a humidified chamber at $4^{\circ} \mathrm{C}$ overnight. The cells were then rinsed three times with $0.05 \%$ Tween-20 in PBS and incubated with a 1:100 dilution of secondary 
antibody for 30 minutes in $0.05 \%$ Tween-20 and 5\% HS in PBS. The cells were then rinsed three times with 0.05\% Tween-20 in PBS. All fluid was then removed, and two separate drops of Gel Mount-4' and 6' diamino-2-phenylindole $2 \mathrm{HCl}$ (DAPI) were applied to the sections. A cover slip was then carefully lowered onto the sections. The cells were then imaged using a TCSSP laser-scanning confocal microscope with a $\times 40$ oil immersion lens (Leica Microsystems, Mannheim, Germany).

\section{Cell invasion assay}

In vitro invasion assay was performed to analyze the invasive potential of stable clone \#6 and clone \#12 cells. A total of $1 \times 10^{5}$ cells in $750 \mu \mathrm{l}$ of serum-free RPMI1640 medium were plated onto BD BioCoat ${ }^{\mathrm{mm}}$ Matrigel ${ }^{\mathrm{IM}}$ Invasion Chambers $(8 \mu \mathrm{m}$ pore size; BD Biosciences, USA) with the lower chamber containing $750 \mu \mathrm{l}$ of RPMI-1640 medium with $10 \%$ FBS as a chemoattractant. After 48 hours of incubation in a humidified atmosphere containing $5 \% \mathrm{CO}_{2}$ at $37^{\circ} \mathrm{C}$, the non-invading cells were removed from the upper surface of the membrane by a cotton swab. The membranes were then fixed with methanol and stained with $0.5 \%$ crystal violet stain. Invading cells were photographed and counted in five random non-overlapping $200 \times$ fields under a light microscope.

\section{Tumorigenicity in vivo}

Nude mice (4-6 weeks old) were used for xenograft studies. Tca cells $\left(1.5 \times 10^{6}\right.$ in PBS) expressing MAL (clone $\# 12$ ) or not (clone \#6) were injected subcutaneously in the extremities of the nude mice. After four weeks, nude mice bearing tumors were executed, and tumor weight was measured using an electronic balance. The values for nine mice in each group were averaged to obtain the mean \pm (SD) Differences in tumor weights were analyzed using the Student's $t$-test.

\section{Statistical analysis}

Semi-quantitative RT-PCR, real-time PCR and in vitro statistical analyses were performed with software from SPSS 13.0 for Windows (Chicago, IL, USA). Results of the semi-quantitative RT-PCR and real-time PCR analyses were evaluated using the Mann-Whitney test for two independent groups. The results of the cell proliferation assay, colony formation assay, and in vitro invasion assay were evaluated using Student's $t$-tests. A $P$-value of less than 0.05 was considered significant.

\section{Acknowledgements}

We would like to thank Prof. Tokio Osaki (Kochi University, Japan) for providing the OSC-4, and Prof. ZL Wang (Nagasaki University, Japan) for providing the NB and NT cell lines. This study was supported by The
National Natural Science Foundation of China (Grant No. 30330580, 30973343), Projects of the Shanghai Science and Technology Committee (08JC1414400, 09431902200 and 10XD1402500) and the Shanghai Leading Academic Discipline Project (S30206) as well as the Doctoral Innovation Foundation from Shanghai Jiao Tong University School of Medicine (BXJ0925).

\section{Author details}

${ }^{1}$ Department of Oral and Maxillofacial Surgery, Ninth People's Hospital, Shanghai Jiao Tong University School of Medicine, Shanghai 200011, China. ${ }^{2}$ Shanghai Key Laboratory of Stomatology, Shanghai 200011, China. ${ }^{3}$ Chinese National Human Genome Center at Shanghai, 201203, China.

\section{Authors' contributions}

WTC, ZGH, and ZYZ were responsible for the study design, interpretation of the data and revision of the manuscript. WC responsed for the study of growth inhibition in vitro and in vivo, gene overexpression, cell apoptosis and methylation assay. WC, PZ, and MY were responsible for data acquisition, analysis of the work presented and the preparation of the draft of the manuscript. JZ, QX, and QS helped to obtain the tissues and to do the experiment in vivo. WTC, ZGH, and ZYZ supervised the studies and helped to revise the manuscript. All authors read and approved the final manuscript.

\section{Competing interests}

The authors declare that they have no competing interests.

Received: 23 August 2010 Accepted: 22 November 2010 Published: 22 November 2010

\section{References}

1. Mignogna MD, Fedele S, Lo Russo L: The World Cancer Report and the burden of oral cancer. Eur J Cancer Prev 2004, 13(2):139-142.

2. Mohr S, Leikauf GD, Keith G, Rihn BH: Microarrays as cancer keys: an array of possibilities. J Clin Oncol 2002, 20(14):3165-3175.

3. Alevizos I, Mahadevappa M, Zhang X, Ohyama H, Kohno Y, Posner M, Gallagher GT, Varvares M, Cohen D, Kim DI: Oral cancer in vivo gene expression profiling assisted by laser capture microdissection and microarray analysis. Oncogene 2001, 20(43):6196-6204.

4. Belbin TJ, Singh B, Smith RV, Socci ND, Wreesmann VB, Sanchez-Carbayo M, Masterson J, Patel S, Cordon-Cardo C, Prystowsky MB: Molecular profiling of tumor progression in head and neck cancer. Archives of otolaryngologyhead \& neck surgery 2005, 131(1):10-18.

5. Carles A, Millon R, Cromer A, Ganguli G, Lemaire F, Young J, Wasylyk C, Muller D, Schultz I, Rabouel Y: Head and neck squamous cell carcinoma transcriptome analysis by comprehensive validated differential display. Oncogene 2006, 25(12):1821-1831.

6. Chin D, Boyle GM, Williams RM, Ferguson K, Pandeya N, Pedley J, Campbell CM, Theile DR, Parsons PG, Coman WB: Novel markers for poor prognosis in head and neck cancer. Int J Cancer 2005, 113(5):789-797.

7. Kuriakose MA, Chen WT, He ZM, Sikora AG, Zhang P, Zhang ZY, Qiu WL, Hsu DF, McMunn-Coffran C, Brown SM, Elango EM, Delacure MD, Chen FA: Selection and validation of differentially expressed genes in head and neck cancer. CMLS, Cell Mol Life SC 2004, 61(11):1372-1383.

8. Mimori K, Shiraishi T, Mashino K, Sonoda H, Yamashita K, Yoshinaga K, Masuda T, Utsunomiya T, Alonso MA, Inoue H, Mori M: MAL gene expression in esophageal cancer suppresses motility, invasion and tumorigenicity and enhances apoptosis through the Fas pathway. Oncogene 2003, 22(22):3463-3471.

9. Lind GE, Ahlquist T, Kolberg M, Berg M, Eknaes M, Alonso MA, Kallioniemi A, Meling Gl, Skotheim Rl, Rognum TO, Thiis-Evensen E, Lothe RA: Hypermethylated MAL gene - a silent marker of early colon tumorigenesis. J Transl Med 2008, 6:13.

10. Buffart TE, Overmeer RM, Steenbergen RD, Tijssen M, Van Grieken NC, Snijders PJ, Grabsch HI, Van de Velde CJ, Carvalho B, Meijer GA: MAL promoter hypermethylation as a novel prognostic marker in gastric cancer. Br J Cancer 2008, 99(11):1802-1807.

11. Horne HN, Lee PS, Murphy SK, Alonso MA, Olson JA Jr, Marks JR: Inactivation of the MAL gene in breast cancer is a common event that predicts benefit from adjuvant chemotherapy. Mol Cancer Res 2009, 7(2):199-209. 
12. Hatta M, Nagai H, Okino K, Onda M, Yoneyama K, Ohta Y, Nakayama H, Araki T, Emi M: Down-regulation of members of glycolipid-enriched membrane raft gene family, MAL and BENE, in cervical squamous cell cancers. J Obstet Gynaecol Res 2004, 30(1):53-58.

13. Maruya S, Kim HW, Weber RS, Lee JJ, Kies M, Luna MA, Batsakis JG, ElNaggar AK: Gene expression screening of salivary gland neoplasms: molecular markers of potential histogenetic and clinical significance. J Mol Diagn 2004, 6(3):180-90.

14. Alonso MA, Weissman SM: CDNA cloning and sequence of MAL, a hydrophobic protein associated with human T-cell differentiation. Proc Natl Acad Sic USA 1987, 84(7):1997-2001.

15. Kim T, Fiedler K, Madison DL, Krueger WH, Pfeiffer SE: Cloning and characterization of MVP17: a developmentally regulated myelin protein in oligodendrocytes. J Neurosci Res 1995, 42(3):413-422.

16. Simons K, Ikonen E: Functional rafts in cell membranes. Nature 1997, 387(6633):569-572

17. Cheong KH, Zacchetti D, Schneeberger EE, Simons K: VIP17/MAL, a lipid raft-associated protein, is involved in apical transport in MDCK cells. Pro Natl Acad Sci USA 1999, 96(11):6241-6248.

18. Puertollano R, Martín-Belmonte F, Millán J, de Marco MC, Albar JP, Kremer L, Alonso MA: The MAL proteolipid is necessary for normal apical transport and accurate sorting of the influenza virus hemagglutinin in MadinDarby canine kidney cells. J Cell Biol 1999, 145(1):141-151.

19. Wong YF, Cheung TH, Tsao GS, Lo KW, Yim SF, Wang WW, Heung MM, Chan SC, Chan LK, Ho TW, Wong KW, Guo Y, Chung TK, Smith DI: Genomewide gene expression profiling of cervical cancer in Hong Kong women by oligonucleotide microarray. Int J Cancer 2006, 118(10):2461-2469.

20. Mori Y, Cai K, Cheng Y, Wang S, Paun B, Hamilton JP, Jin Z, Sato F, Berki AT, Kan T, Ito T, Mantzur C, Abraham JM, Meltzer SJ: A Genome-wide search identifies epigenetic sliencing of somatostain, tachykinin- 1 and 5 other genes in colon cancer. Gastroenterology 2006, 131(3):797-808.

21. Beder LB, Gunduz M, Hotomi M, Fujihara K, Shimada J, Tamura S, Gunduz E, Fukushima K, Yaykasli K, Grenman R, Shimizu K, Yamanaka N: T-lymphocyte maturation-associated protein gene as a candidate metastasis suppressor for head and neck squamous cell carcinomas. Cancer Sci 2009, 100(5):873-880

22. Berchuck A, Iversen ES, Luo J, Clarke JP, Horne H, Levine DA, Boyd J, Alonso MA, Secord AA, Bernardini MQ, Barnett JC, Boren T, Murphy SK, Dressman HK, Marks JR, Lancaster JM: Microarray analysis of early stage serous ovarian cancers shows profiles predictive of favorable outcome. Clin Cancer Res 2009, 15(7):2448-2455.

23. Rancaño C, Rubio T, Alonso MA: Alternative splicing of human T-cellspecific MAL mRNA and its correlation with the exon/intron organization of the gene. Genomics 1994, 21(2):447-450.

24. Herman JG, Graff JR, Myöhänen S, Nelkin BD, Baylin SB: Methylationspecific PCR: a novel PCR assay for methylation status of CPG islands. Proc Natl Acad Sci USA 1996, 93(18):9821-9826.

25. Boulares AH, Yakovlev AG, Ivanova V, Stoica BA, Wang G, lyer S, Smulson M: Role of poly(ADP-ribose) polymerase (PARP) cleavage in apoptosis. Caspase 3-resistant PARP mutant increases rates of apoptosis in transfected cells. J Biol Chem 1999, 274(33):22932-22940.

26. Tomioka H, Morita K, Hasegawa S, Omura K: Gene expression analysis by cDNA microarray in oral squamous cell carcinoma. J Oral Pathol Med 2006, 35(4):206-211.

27. Ziober AF, Patel KR, Alawi F, Gimotty P, Weber RS, Feldman MM, Chalian AA, Weinstein GS, Hunt J, Ziober BL: Identification of a gene signature for rapid screening of oral squamous cell carcinoma. Clin Cancer Res 2006, 12(20 Pt 1):5960-5971.

28. Ye H, Yu T, Temam S, Ziober BL, Wang J, Schwartz JL, Mao L, Wong DT, Zhou $X$ : Transcriptomic dissection of tongue squamous cell carcinoma. BMC Genomics 2008, 9:69.

29. Choi P, Jordan CD, Mendez E, Houck J, Yueh B, Farwell DG, Futran N, Chen C: Examination of oral cancer biomarkers by tissue microarray analysis. Arch Otolaryngol Head Neck Surg 2008, 134(5):539-546.

30. Marte B, Eccleston A, Nath D: Molecular cancer diagnostics. Nature 2008, 452(7187):547.

31. Lallemant B, Evrard A, Combescure C, Chapuis H, Chambon G, Raynal C, Reynaud C, Sabra O, Joubert D, Hollande F, Lallemant JG, Lumbroso S, Brouillet JP: Clinical relevance of nine transcriptional molecular markers for the diagnosis of head and neck squamous cell carcinoma in tissue and saliva rinse. BMC Cancer 2009, 9:370.
32. Martín-Belmonte F, Arvan P, Alonso MA: MAL mediates apical transport of secretory proteins in polarized epithelial Madin-Darby canine kidney cells. J Biol Chem 2001, 276(52):49337-49342.

33. Martín-Belmonte F, Puertollano R, Millán J, Alonso MA: The MAL proteolipid is necessary for the overall apical delivery of membrane proteins in the polarized epithelial Madin-Darby canine kidney and fischer rat thyroid cell lines. Mol Biol Cell 2000, 11(6):2033-2045.

34. O'Regan EM, Toner ME, Finn SP, Fan CY, Ring M, Hagmar B, Timon C, Smyth P, Cahill S, Flavin R, Sheils OM, O'Leary JJ: p16(INK4A) genetic and epigenetic profiles differ in relation to age and site in head and neck squamous cell carcinomas. Hum Pathol 2008, 39(3):452-458.

35. Konrad M, Saunier S, Heidet L, Silbermann F, Benessy F, Calado J, Le Paslier D, Broyer M, Gubler MC, Antignac C: Large homozygous deletions of the $2 q 13$ region are a major cause of juvenile nephronophthisis. Hum Mol Genet 1996, 5(3):367-371.

36. Overmeer RM, Henken FE, Bierkens M, Wilting SM, Timmerman I, Meijer CJ, Snijder PJ, Steenbergen RD: Repression of MAL tumour suppressor activity by promoter methylation during cervical carcinogenesis. J Pathol 2009, 219(3):327-336.

37. Lee PS, Teaberry VS, Bland AE, Huang Z, Whitaker RS, Baba T, Fujii S, Secord AA, Berchuck A, Murphy SK: Elevated MAL expression is accompanied by promoter hypomethylation and platinum resistance in epithelial ovarian cancer. Int J Cancer 2010, 126(6):1378-1389.

38. Ahlquist T, Lind GE, Costa VL, Meling Gl, Vatn M, Hoff GS, Rognum TO, Skotheim Rl, Thiis-Evensen E, Lothe RA: Gene methylation profiles of normal mucosa, and benign and malignant colorectal tumors identify early onset markers. Mol Cancer 2008, 7:94.

39. Sobin LH, Fleming ID: TNM Classification of Malignant Tumors, fifth edition (1997). Union Internationale Contre le Cancer and the American Joint Committee on Cancer. Cancer 1997, 80(9):1803-1804.

40. Loiaconi G, Berth AF: Current aspects of histological typing of carcinomas of the oral cavity. Riv Ital Stomatol 1982, 51(5):415-421.

\section{doi:10.1186/1476-4598-9-296}

Cite this article as: Cao et al:: Epigenetic silencing of $M A L$, a putative tumor suppressor gene, can contribute to human epithelium cell carcinoma. Molecular Cancer 2010 9:296.

\section{Submit your next manuscript to BioMed Central and take full advantage of:}

- Convenient online submission

- Thorough peer review

- No space constraints or color figure charges

- Immediate publication on acceptance

- Inclusion in PubMed, CAS, Scopus and Google Scholar

- Research which is freely available for redistribution

Submit your manuscript at www.biomedcentral.com/submit
C Biomed Central 